\title{
The Research of Using Fly Ash Based Polymer Materials to Immobilize Iodine Ion
}

\author{
Chen $\mathrm{CHEN}^{*}$ \\ School of Environmental and Chemical Engineering \\ Jiangsu University of Science and Technology \\ Zhenjiang 212003, China \\ e-mail: chenc@just.edu.cn
}

\section{Fan FENG}

School of Environmental and Chemical Engineering Jiangsu University of Science and Technology Zhenjiang 212003, China

\author{
Rui-yang LV \\ School of Environmental and Chemical Engineering \\ Jiangsu University of Science and Technology \\ Zhenjiang 212003, China
}

\begin{abstract}
The article discusses the immobilization on Iodine ion by using fly ash based geopolymer materials, the compressive strength, XRD and IR patterns vary with the amount of immobilization. The leaching experiment and the fitting of leaching kinetics data are done on the previous basis. The experimental result indicates that addition of Iodine ion does not have a significant effect on the macroscopic strength and micro-structure of fly ash polymer. The leaching speed of Iodine ion in the water is fast in early times and reduces gradually in the late time and the early-stage process could be fitted by Jander equation.
\end{abstract}

Keywords- Fly ash, Geopolymer, I, Immobilization.

\section{INTRODUCTION}

Geopolymer is one general kind of artificial synthetic silicon aluminum material. The French scientist called Davidovits is the first one to put forward the concept of poly-aluminum-silicate materials at JUPAC in 1976. Geological polymers have shown superior performances than traditional cement-concrete materials in many aspects such as macro-mechanics, durable and high-temperature resistant and corrosion resistant and so on. Besides these, in the process of the synthesis, it avoids discharging a large amount of carbon dioxide from cement production during the calcining process. Therefore, geopolymer is commonly regarded as environment-friendly substitution of traditional cement-concrete materials.

Currently, the research of geopolymer has extended gradually from the initial cement-concrete replacement-materials to the dangerous and harmful wastes in the field of immobilization. Zhang and some other scientists successfully use fly ash as the raw material to achieve the synthesis of geopolymer material that has immobilized solution of chromium ions, lead ions and cadmium ions and put forward a theory that the joint polluted ions does not change the inner structure of geopolymer in the meantime. Perera uses the kaolin to complete the synthesis of geological polymer materials in potassium-alkali-excitation condition to have immobilized $1 \%$ nitrate solution and it is monitored to have the leaching liquid by TCLP and the ion concentration is $2.8 \mathrm{ppm}$, which is lower than the standard of $5 \mathrm{ppm}$ regulated by the federal environmental protection agency in the United States. Hanzlicek uses geopolymer materials to immobilize radioactive isotopes such as $\mathrm{EU}, \mathrm{Cs}$, $\mathrm{Co}$ and $\mathrm{Fe}$, and the result shows that there is no obvious phenomenon of leaching in the water even if under the circumstance even the solidified body is polished into powder and these ions remain in the polymer reaction products. This article uses fly ash basic polymer as the material to immobilize Iodine ion that is common in the radioactive wastes, analyzes and studies the macro strength and micro-structure of curing materials and the leaching test is conducted. Based on this, we get the leaching dynamic equations of Iodine ion and achieve the purpose of using wastes to treat wastes at the same time.

\section{EXPERIMENTAL MATERIALS AND METHODS}

The experimental drugs are all chemically pure, the samples of fly ash are taken from Jiangsu Taicang Xiexin power plants, the main chemical components are shown in chart 1 . The experimental instruments include: DKZ-series electrothermal constant-temperature sink, Diane corporation ICS90A-type ion spectrum,XRD-6000 X-Ray diffractometer from Daojin company,FTIR-7600 Fourier infrared spectrometer from Laomode in Australia,IF-1A standard curing box,TYE-500A bending compression Testing-machine.

Put the samples of fly ash that weighs $500 \mathrm{~g}$ into planetary mixer, keep stirring for two minutes at the speed of 62RPM, add alkali solution during the $\operatorname{stir}(8 \mathrm{~mol} / \mathrm{L}$ sodium hydroxide solution), the weight of iodine ion in alkali solution is $2.5 \sim 7.5 \mathrm{~g}(0.5 \sim 1.5 \%$ of the weight of fly ash, prepared from potassium iodide). Clean up the leftovers of serous in stirring pot and mixing blade edge to stirring pot. After finishing that, keep stirring for two minutes at the speed of 125RPM, then put the serous into the models of $1.5 \mathrm{~cm} \times 1.5 \mathrm{~cm} \times 1.5 \mathrm{~cm}$, finally put the samples into curing box for maintenance, remain the maintenance of humidity at $100 \%$, the curing temperature is $75^{\circ} \mathrm{C}$, the curing time is $24 \mathrm{~h}$.

Take the samples from curing box after maintenance, take off the film processing when the temperature is down to the room temperature, then the rest of the samples use 
TYE-500A bending compression Testing-machine to conduct the compressive strength test, other parts will be used for the research of leaching experiment.

Put the samples into $500 \mathrm{ml}$ beaker after maintenance, add $300 \mathrm{ml}$ deionized water (the specific weight of water is 10 times as much as the leaching samples), then put the beaker into constant-temperature water bath for leaching experiment, the temperature of leaching experiment remains at $25^{\circ} \mathrm{C}$, the leaching time is $0 \sim 140 \mathrm{~h}$. After leaching, take out the solution in beaker, use ion chromatogarph to test iodine ion after $0.5 \mu \mathrm{m}$ membrane filter.

\section{EXPERIMENTAL RESULTS AND DISCUSSIONS}

\section{A. Mechanical Strength}

The Fig1 1 shows the compressive strength of geopolymer samples. We can also see from the Fig 1 that amount of curing of iodine ion does not have a significant effect on the intensity of the macro strength of geopolymer materials and no linear relationship between them.

Three different compressive strength of the geopolymer materials under curing conditions are $5.1 \mathrm{MPa}(0.5 \%)$, 5.3 $\mathrm{MPa}(1 \%)$ and $4.98 \mathrm{MPa}(1.5 \%)$ respectively. This implies that the addition of iodine ion cannot change the main reaction process and micro-structure of geopolymer materials obviously.

\section{B. XRD and IR}

The Fig 2 shows X-Ray diffraction spectra of geopolymer samples. Only the characteristic diffraction peak of quartz and mullite exist in X-Ray diffraction spectra of three reaction products, no diffraction peak of any other new minerals is observed. Such result is consistent with the achievements of other researchers, which means that the reaction products of geopolymer can just be the non-neat-structure and amorphous gel. On the other hand, it means the addition of iodine ion does not have a significant effect on the main reaction and structure of the geopolymer.

The Fig 3 shows the results of infrared spectrum analysis of geopolymer samples. We can see that the group $\mathrm{Si}-\mathrm{O}-\mathrm{Si}$ in the infrared spectrum of geopolymer reaction products of vibrates in asymmetric scale at $1085 \mathrm{~cm}^{-1}$ and the group $\mathrm{O}-\mathrm{Si}-\mathrm{O}$ vibrates in plane bending at $466 \mathrm{~cm}^{-1}$, and then they become the asymmetric stretching vibration at $987 \mathrm{~cm}^{-1}$ and plane bending vibration at $428 \mathrm{~cm}^{-1}$ compared to the previous fly ash. According to literature, the transfer of vibration peak means the dissolve of fly ash vitreous and the form of geopolymer main structure. Besides, the amount of three different infrared spectrums of iodine ion samples are pretty similar, which further proves that the addition of iodine ion does not have a negative effect on the main reaction and structure.

\section{Leaching Results}

The Fig 4 shows the leaching experimental results of geopolymer samples in the water.As we can see,the leaching process of geopolymer samples can be mainly divided into two stages.
Take the amount of curing at $1.5 \%$ for example, in 12 hours before the leaching experiment, the leaching speed is quite fast. The leaching rate of iodine ion rises from $0.14 \%$ to $0.90 \%$ and the average leaching speed is $0.063 \% / \mathrm{h}$. With the processing of leaching reaction, the leaching speed drops gradually and the leaching rate of iodine ion only rises from $0.90 \%$ to $1.67 \%$ when the leaching time lasts from 12 hours to 144 hours, the average speed drops to $0.0000598 \% / \mathrm{h}$, the other two samples have similar results. It is mainly because that the early leaching reaction occurs at the surface of solid phase or somewhere that is near the surface and leaching concentration differs too much, which leads to fast leaching speed. In later time, leaching reaction gradually expands to the inner space of solid phase and leaching concentration difference becomes smaller, thus the leaching speed gradually begins to slow down.

\section{The Kinetics of Leaching}

For the general quick stage of solid and liquid leaching process, the equation of Jander is commonly used for the simulation of kinetic process, the specific form of equation is shown in the following. The Fig 5 shows the result of quick leaching stage statistics after the simulation of Jander equation, we can see that three amount of curings of iodine ions of geopolymer samples can be simulated by this equation at the aboved statistics, In the early 12 hours, the simulation results of the square of $\mathrm{R}$ are all more than 0.97 ,the reaction rate constants are $0.00026(1.5 \%)$, $0.00017(1 \%)$ and $0.00013(0.5 \%)$ respectively.

\section{CONCLUSIONS}

The article makes the research about the process of immobilizing iodine ion of fly ash basic polymer materials. The experimental result indicates that the addition of iodine ion cannot have the negative influences on the intensity of macro and micro-structure of geopolymer materials. The leaching process of iodine ion in the water can exist in both the stage of quick leaching and slow leaching .Jander equation can well simulate the leaching process in quick leaching stages.

\section{ACKNOWLEDGMENTS, APPENDICES, FOOTNOTES AND THE BIBLIOGRAPHY}

This work was financial supported by the Natural Science Foundation of China (NSFC) (Grant No. 21407068), Science Foundation of Jiangsu Colleges and Universities (Project No. 14KJD610002), 2016 University of Jiangsu Province Blue Project of young academic leader training objects, Open Fund Project of Jiangsu Provincial Key Laboratory of Environmental Engineering (Grant No. KF2014002, KF2015011), Jiangsu College Students' Innovation and Entrepreneurship Training Program (Project No. 201614000005Y).

\section{REFERENCES}

[1] J.Davidovits,Journal of Thermal Analysis (UK).8,1633 (1991).

[2] J. Davidovits,Journal of Thermal Analysis and Calorimetry. 35,429 (1989). 
[3] DavidovitsJ. Mineral polymers and methods of making them. US Patent No. 4349386, 1982.

[4] J. G.Zhang,J. L. Provis andD. W.Feng,J. hazard. Mater. 157 (2008)587.

[5] D. S.Perera , Y. Z.Al, Communications of the American Ceramic Society, $\mathbf{9 , 2 5 8 6}$ (2005).
[6] T.Hanzlicek, M. Steinerova andP.Straka, J. Am. Ceram. Soc, 11,3541 (2006).

[7] C.Chen,Q.Li, L. F.Shen,Environ. Technol.11, 1313 (2012).

[8] A.Ferna'ndez-Jime'nez and A.Palomo,Mesopor Mat. 3, 207 (2005).

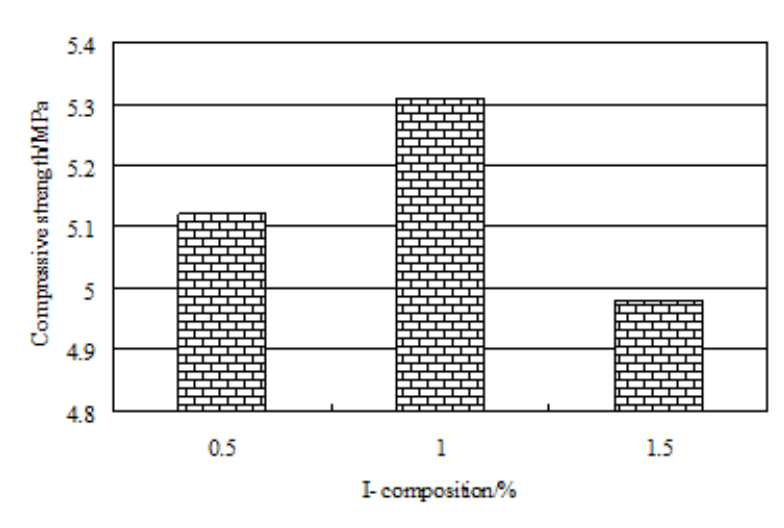

Figure 1. Compressive strength of geopolymer samples

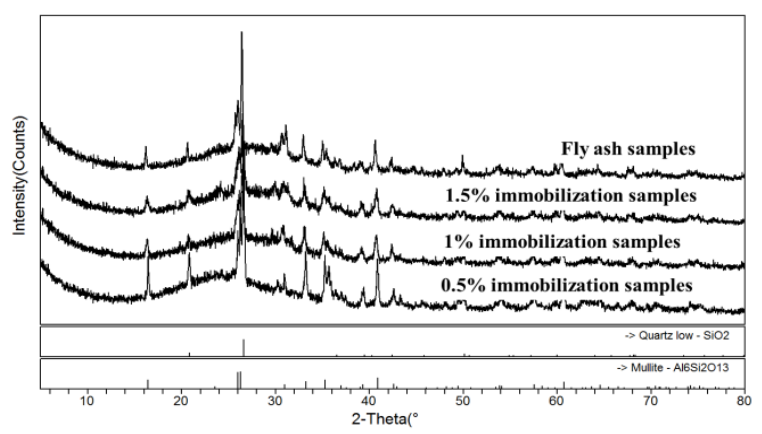

Figure 2. XRD patterns of fly ash and immobilization samples

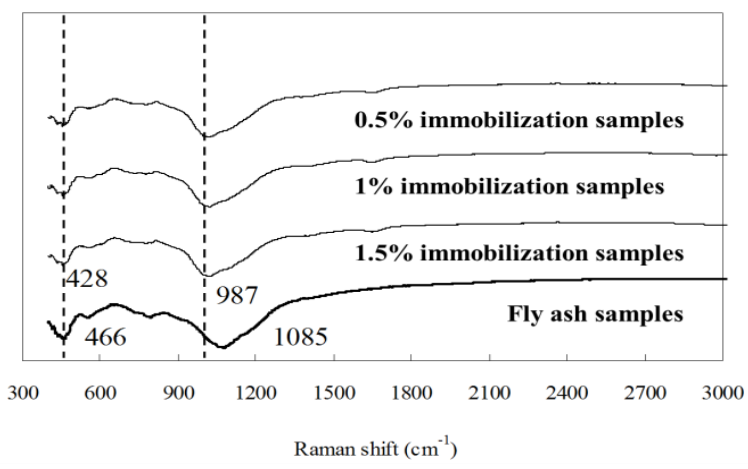

Figure 3. IR spectra of fly ash and immobilization samples 


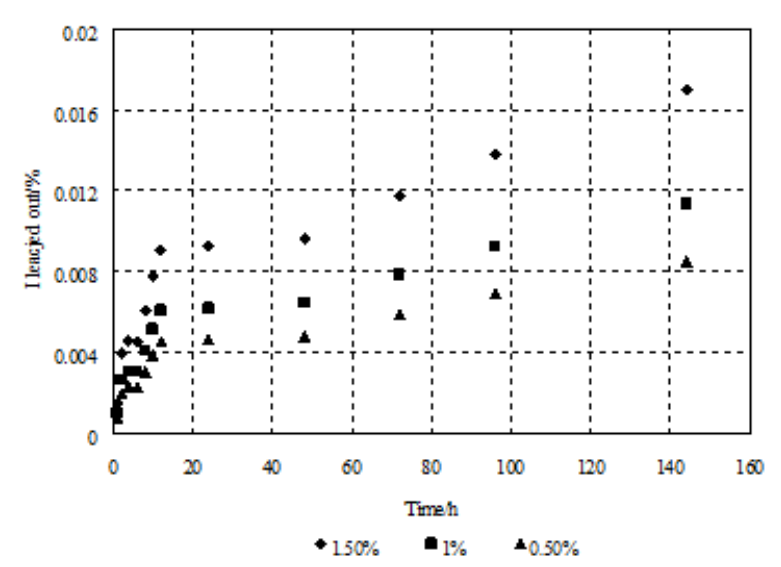

Figure 4. Leaching results of immobilization samples

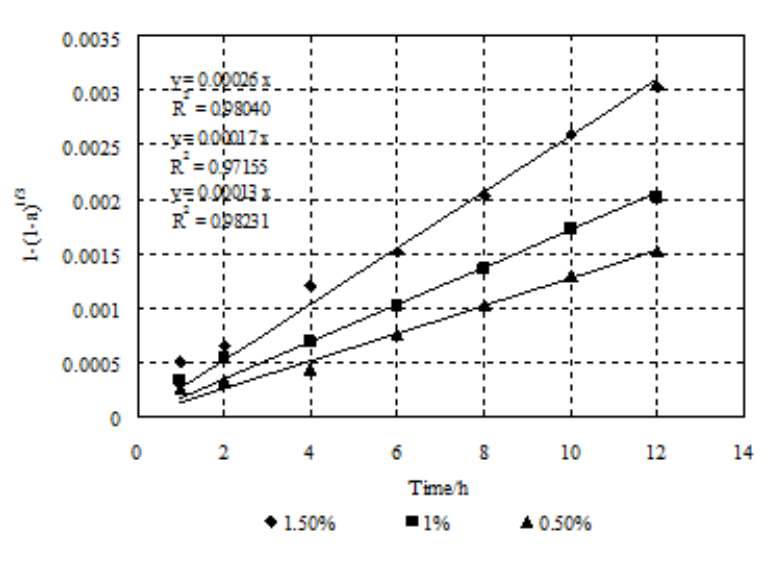

Figure 5. Leaching kinetics analysis of immobilization samples 